\title{
Is COVID-19 Gender-sensitive?
}

\author{
Shreya Mukherjee ${ }^{1,2} \cdot$ Kalipada Pahan ${ }^{1,3}$
}

Received: 16 October 2020 / Accepted: 26 November 2020 / Published online: 6 January 2021

(C) The Author(s), under exclusive licence to Springer Science+Business Media, LLC part of Springer Nature 2021

\begin{abstract}
While clinical characteristics exhibit that susceptibility to COVID-19 infection is equally likely between males and females, clinical outcomes show that males experience both a higher severity and fatality for COVID-19 infection than females. This review examines the evidence for these sex and gender differences and aims to illustrate possible mechanisms behind such sensitivity. Successful entry of SARS-CoV-2 into the body is dependent on the angiotensin-converting enzyme 2 (ACE2) receptor and the transmembrane protease serine 2 (TMPRSS2). Thus, sex-based differences in the expression of the ACE2 receptor and TMPRSS2 may explain the disparities in COVID-19 severity and fatality. Furthermore, these disparities may also be attributed to sex-based difference in immunological responses. Finally, the differences in clinical outcomes of COVID-19 infections between men and women may be due to gendered differences in behaviors, such as smoking, and prevalence to comorbidities. An understanding of the sex and gender sensitivities of COVID-19 infection is a necessary component towards the creation of effective treatment options and therapies for the virus.
\end{abstract}

Keywords COVID-19 $\cdot$ Gender $\cdot$ ACE- $2 \cdot$ TMPRSS $2 \cdot$ Hypertension

\section{Introduction}

In December 2019, several cases of pneumonia from an unidentified origin emerged in Wuhan, Hubei, China. These cases were attributed to the novel betacoronavirus named SARS-CoV-2 (severe acute respiratory syndrome coronavirus 2) (Guan et al. 2020). SARS-CoV-2 is the virus responsible for the severe respiratory disease referred to as coronavirus disease 19 (COVID-19), which has been declared a pandemic by the World Health Organization (WHO) on March 11, 2020 (Gebhard et al. 2020; Machhi et al. 2020; Yuen et al. 2020). As of October 13, 2020, there have been 38,032,320 reported cases of COVID-19 and 1,084,336 deaths, representing a $2.85 \%$ worldwide fatality rate.

Kalipada Pahan

Kalipada_Pahan@rush.edu

1 Department of Neurological Sciences, Rush University Medical Center, 1735 West Harrison St Suite Cohn 310, Chicago, IL 60612, USA

2 Present address: Honors Program in Medical Education, Northwestern University, Chicago, IL, USA

3 Division of Research and Development, Jesse Brown Veterans Affairs Medical Center, Chicago, IL, USA
Additionally, as early as March 2020, reports began to suggest differences in prevalence to and severity of COVID19 infection (Cai 2020). Early studies indicated a higher susceptibility of males to COVID-19 infection, but accumulating epidemiological evidence has not shown sex or gender disparities in COVID-19 susceptibility (Ambrosino et al. 2020). Furthermore, recent studies and examinations of clinical characteristics corroborated early observations that males tend to experience higher severity and fatality of COVID-19 cases (Gebhard et al. 2020; Jin et al. 2020). In fact, a recent analysis of COVID-19-related deaths found that mortality was 1.77 times higher for males than females (Yanez et al. 2020).

At present, there are no specific treatments or antiviral agents for SARS-CoV-2, but many possible therapies are being investigated. These include targeting axes of the reninangiotensin system (RAS), blocking the receptor binding domain of the viral S-protein, camostat mesylate, and cathepsin L/B inhibitor (Gheblawi et al. 2020). The most common symptoms of COVID-19 infection are fever, cough, fatigue, and shortness of breath (Ambrosino et al. 2020; Tian et al. 2020). Deaths from COVID-19 are associated with acute respiratory distress syndrome (ARDS), acute respiratory failure, coagulopathy, septic shock, and metabolic acidosis (Wortham et al. 2020). Several comorbidities have been shown to increase severity of the disease and risk of death (Pahan and 
Pahan 2020; Zhou et al. 2020). The most common comorbidities include hypertension, diabetes, cardiovascular disease, chronic lung disease, and chronic kidney disease (Gebhard et al. 2020; Wortham et al. 2020; Zhou et al. 2020). Additionally, age has been associated with greater risk for poor clinical outcomes (Vaduganathan et al. 2020; Wortham et al. 2020). Of the entire patient population, the poorest outcome was observed in elderly populations with cardiovascular disease with a case fatality rate of $10.5 \%$ (Gebhard et al. 2020).

Given the disparities of clinical outcomes on the basis of sex and gender, there is a need to identify possible genderspecific factors in COVID-19 and thus target these factors for therapies as well. Therefore, we have devoted the following sections to analyze sex and gender differences in COVID-19 with possible molecular mechanisms and avenues to control such pathways.

\section{Gender Sensitivity in COVID-19 Infection}

Clinical data regarding COVID-19 show no significant sex differences in susceptibility to COVID-19 infection. An analysis of the public data set from the Chinese Public Health Science Data Center contained the first 37 fatalities from COVID-19 and 1,109 cases of COVID-19 survivors. The analysis showed that male and female patients displayed the same susceptibility to COVID-19 infection (Jin et al. 2020). In a study of 44,672 confirmed cases taken from China's Infectious Disease Information System through February 11, 2020 , it was found that $51.4 \%$ of patients with confirmed cases of COVID-19 were male (Team 2020). In a contracttracing effort in the United States, the Maine Center for Disease Control and Prevention (CDC) enrolled 1,622 contacts of 614 patients with COVID-19 in an automated symptom-monitoring tool between May 14, 2020 and June 26, 2020. Among these enrollees, 190 developed COVID-19; and, among these patients, $52.1 \%$ were female, and $47.9 \%$ were male (Krueger et al. 2020). Furthermore, an analysis of the $1,320,488$ confirmed COVID-19 cases in the United States reported from January 22, 2020 to May 30, 2020 found that the incidence of cases was similar between females and males. Among the total reported patients, 646,358 $(48.9 \%)$ were male, and $674,130(51.1 \%)$ were female. Furthermore, the cumulative incidence for males was 401.1 cases per 100,000 , and that of females was 406.0 cases per 100,000 (Stokes et al. 2020). Interestingly, this particular report from the United States shows a higher percentage of cases in females than males. Data regarding confirmed COVID-19 cases, as of April 1, 2020, from China, Italy, Spain, France, Germany, and Switzerland showed that there were no significant sex disparities in the absolute number of cases of COVID-19. However, it was noted that this could indicate a higher incidence of COVID-19 among older males, as the absolute number of older males is less than that of females. Data from Germany and Switzerland support this assertion; it was found that there was an increased incidence of COVID-19 infection in males greater than 60 years old (Gebhard et al. 2020).

\section{Gender Sensitivity in COVID-19 Mortality}

There is substantial evidence that points to gender and sex sensitivities in COVID-19 severity, and males experience more severe COVID-19 cases. In addition to increased severity, several studies have shown that male COVID-19 patients have a higher fatality rate than female patients.

\section{Greater Death Among Males Than Females From COVID-19 in China}

A case series analysis of 43 patients in Wuhan, China found that male patients' cases of COVID-19 were more likely to be serious than those of female patients. The median age of these patients was 62 years old, and there was no significant difference in the ages of the male and female patients. Furthermore, among this data set, $37.2 \%$ had underlying disorders including hypertension, cardiovascular diseases, diabetes, and lung diseases; however, there were no significant differences in comorbidities between the male and female patients. Additionally, an analysis of COVID-19 cases from the Chinese Public Health Science Data Center found that, among the deceased patients, the number of male patients was 2.4 times greater than that of female patients. The median age for the deceased patients was 70.3 years old, and there were no significant differences in ages between the male and female patients in this data set. Furthermore, among the deceased patients, 64.9\% had comorbidities (Jin et al. 2020). Analysis of a data set of 41 COVID-19 patients from December 16, 2019 to January 2, 2020, found that there was a greater proportion of male patients admitted to the intensive care unit (ICU). The median age of these patients was 49 years old. Furthermore, $32 \%$ of the patients had underlying conditions, including diabetes, hypertension, and cardiovascular disease. Among all the patients in this data set, 30 were male $(73 \%)$ and 11 were female $(27 \%)$. However, among the 13 patients admitted to the ICU, 11 were male $(85 \%)$ and 2 were female (15\%) (Huang et al. 2020).

A study of 262 COVID-19 patients in Beijing between January 20, 2020 and February 10, 2020 also found that males made up a greater percentage of those with severe cases. The age range of patients was from 6 months to 94 years old, and the median was 47.5 years old. Additionally, $77.4 \%$ of the patients were aged between 13 and 64 years old. Among the total cases, $48.5 \%$ were male; however, among the 46 severe cases, $56.5 \%$ were male patients (Tian et al. 2020). A retrospective study was conducted regarding 191 patients 
diagnosed with COVID-19 in Wuhan, China between December 29, 2019 and January 31, 2020. The age range for all of the patients was 18 to 87 years old, and the median age was 56 years old. Nearly half $(48 \%)$ of the patients had comorbidities, the most common being hypertension. Additionally, while $62 \%$ of the total patients were male, the study found that males made up $70 \%$ of the deceased patients (Zhou et al. 2020). In the study of 44,672 COVID-19 cases from China's Infectious Disease Information System, taken through February 11, 2020, a total of 1,023 deaths occurred. Among these patients, $77.8 \%$ were between the ages of 30 and 69 years old. Furthermore, data regarding comorbidities was collected for 20,812 patients, and about $25.5 \%$ of those patients had comorbidities. Furthermore, while $51.4 \%$ of the total patient population was male, $63.8 \%$ of the deceased population was male. Additionally, it was found that the case fatality rate for males was higher than that of females: $2.8 \%$ versus $1.7 \%$, respectively (Team 2020).

\section{Gender Difference in COVID-19-related Deaths in USA}

These gendered differences are also observed in the United States. In one study, the COVID-19-Associated Hospital Surveillance Network (COVID-NET) monitored COVID19-related hospitalizations between March 1, 2020 and March 28, 2020. Majority of the patients that were hospitalized were over the age of $50(74.5 \%)$. Data regarding underlying conditions was only collected for 178 hospitalized patients, and $89.3 \%$ of those patients had one or more underlying conditions. Furthermore, among the 1,482 patients hospitalized with COVID-19, 54.4\% were male. The population makeup of the COVID-NET area is about $49 \%$ male and $51 \%$ female, showing that males were disproportionately hospitalized with COVID-19 in comparison to females (Garg et al. 2020). Between February 12, 2020 and May 18, 2020, 52,166 deaths from 47 jurisdictions were reported to the CDC. In this data set, majority of the patients were above 65 years old $(79.6 \%)$, and the median age was 78 years old. Data regarding comorbidities was not collected for this data set. Among the deceased patients, 55.4\% were male. Furthermore, the CDC collected data regarding 10,647 deaths from 56 public health departments regarding deaths related to COVID-19 between February 12, 2020 and April 24, 2020. In this report, the median age was 75 years old, and at least one comorbidity was reported for $76.4 \%$ of the patients. Among these deceased patients, $60.6 \%$ were male. In both cases, male patients made up a larger percentage of the deceased patients (Wortham et al. 2020). Furthermore, an analysis of 1,320,488 cases of COVID-19 in the United States reported between January 22, 2020 to May 30, 2020 was conducted. The median age of the patients was 48 years old, and $22 \%$ of these cases were associated with underlying conditions. The most common conditions were cardiovascular disease, diabetes, and chronic lung disease; and, the proportion of these comorbidities in male and female patients were comparable. Analysis of these cases found that male patients experienced more severe outcomes than female patients. The report showed that males had a higher rate of hospitalization than female patients ( $15.6 \%$ vs. $12.4 \%$, respectively); males had a higher rate of admission to the ICU than female patients $(2.8 \%$ vs. $1.7 \%$, respectively); and, males had a higher fatality rate than female patients (6.0\% vs. $4.8 \%$ ) (Stokes et al. 2020).

\section{COVID-19 is More Deadly Among Males Than Females in Europe}

These trends are seen in European countries, as well. In Switzerland and France, data regarding COVID-19-related hospitalization find that, although there is no displayed gender or sex sensitivity in incidence of COVID-19, there are 50\% more male patients hospitalized than female patients. In Switzerland, incidence of COVID-19 in males and females is similar across age groups, but hospitalization is 1.5 times higher for male patients. Furthermore, composite COVID-19 data from Germany, Italy, Spain, and Switzerland, comprising of 14,364 deaths, consistently show that the case fatality rate for males is higher than that of females across all age groups. This greater case fatality in male patients was observed across all age groups (Gebhard et al. 2020). In the Lombardy region of Italy, a retrospective study of ICU patients in 72 hospitals was conducted. Among the 1591 patients treated between February 20, 2020 and March 18, 2020, 82\% were male and $18 \%$ were female, displaying a higher proportion of males among the ICU patients. In this data set, the median age was 63 years old, and the relative proportions of males and females in each age group was similar. Furthermore, of the patients on whom data regarding comorbidities were collected, $68 \%$ had at least one comorbidity (Grasselli et al. 2020). Finally, reports from Germany as recent as September 2, 2020 show that male patients represent a greater proportion of deceased patients. Though males make up 49\% of total cases in Germany, they make up $55 \%$ of the total deaths related to COVID-19 (COVID-19 daily situation report of the Robert Koch Institute 2020).

\section{Possible Underlying Mechanisms Behind Gender Sensitivity}

\section{Gender Difference in ACE2 Distribution}

SARS-CoV-2, the virus responsible for COVID-19, enters the body through the angiotensin-converting enzyme 2 (ACE2) (Hoffmann et al. 2020). Differences in the expression of ACE2 caused by sex hormones may help in explaining the sex disparities in COVID-19 infection, severity, and fatality. ACE2 is an enzyme that is involved in the renin-angiotensin 
aldosterone system (RAAS), a hormone system that plays a role in the regulation of blood pressure, tissue perfusion, and balance of the body's extracellular environment. In the process of the RAAS, the hormone renin converts angiotensinogen to the hormone angiotensin I (Ang I), the biologically inert precursor to angiotensin II (Ang II), a vasoconstrictor. The conversion of Ang I to Ang II is mediated by the angiotensin-converting enzyme (ACE). ACE2, on the other hand, negatively regulates the formation of Ang II in the RAAS by hydrolyzing it to the hormone Ang-(1-7), a vasodilator (Vickers et al. 2002; Zaman et al. 2002).

Though COVID-19 is largely understood to be a respiratory disease, emerging evidence has shown that it can directly affect other organs in the body. ACE2 is expressed throughout the body and can be found in the lungs, cardiovascular system, central nervous system, gut, kidneys, and adipose tissue (Gheblawi et al. 2020). Because of the wide expression of ACE2 throughout the body, studies have suggested that SARS-CoV-2 can impact all of these organs (Jain 2020). Particularly, one study regarding postmortem COVID-19 patients found SARS-CoV-2 antigens in the tubular epithelial cells of the kidneys, suggesting that SARS-CoV-2 can directly infect the kidney (Martinez-Rojas et al. 2020). Furthermore, another study found that SARS-CoV-2 infected human induced pluripotent stem cell-derived cardiomyocytes, displaying the direct effects of SARS-CoV-2 on the heart cells (Sharma et al. 2020). Thus, variable expression of ACE2 throughout the body due to sex hormones may elucidate the sex differences in COVID-19 outcomes. Data suggest that a higher expression and activity of ACE2 may increase vulnerability to COVID-19 infection and fatality. For example, one study found that ACE2 expression was high in the lungs of patients with comorbidities associated with higher risk to COVID-19 infection (Pinto et al. 2020).

It has been found that higher ACE2 expression and activity in males than females may contribute to sex differences in COVID-19 infection and fatality. Many studies have noted that ACE2 activity is higher in males than in females (Cai 2020; Gargaglioni and Marques 2020). In a model of hypertensive rats, it was found that cardiac ACE2 activity was higher in male rats (Chappell et al. 2014). Another model on spontaneously hypertensive rats found that overall ACE2 activity was significantly higher in male rats than females (Dalpiaz et al. 2015). This study also found that orchiectomy reduced cardiac ACE2 activity in male rats, and ovariectomy increased ACE2 activity in female rats, suggesting the influence of sex hormones on ACE2 activity in the heart (Dalpiaz et al. 2015). Another study showed that ACE2 activity in the kidney was 1.9 times higher in male mice than females; and, expression of ACE2 in the kidney was 1.5 times higher in male mice than females (Liu et al. 2010). It was also found that ovariectomy of female mice increased renal ACE2 expression. Furthermore, in comparison to gonadectomized mice, estradiol reduced ACE2 activity in the kidneys by $56-59 \%$. This suggests that estrogen has an inhibitory effect on renal ACE2 activity under nonpathological conditions. Though there was an observable sex difference in renal ACE2 activity, this study found no sex differences in ACE2 activity in the heart or lungs under nonpathological conditions (Liu et al. 2010). A recent study found that estrogen regulated the expression of ACE2 in human bronchial epithelial cells. In this study, $17 \beta$-estradiol was applied to normal human bronchial epithelial cells from a female donor, resulting lower levels of ACE2 mRNA. Given that ACE2 is the entry point of SARS-CoV-2 in the body, the decrease in ACE2 mRNA by estradiol may explain the lower severity and fatality of COVID-19 in female patients. However, this study only examined ACE2 mRNA, so further research needs to be done regarding ACE2 expression and activity in the human bronchial epithelium, and with a greater sample size of donors (Stelzig et al. 2020). These slight discrepancies in ACE2 expression throughout the body warrant additional research, specifically regarding the effects of sex hormones on the expression of ACE2 in heart and lungs. Additionally, studies have revealed the expression of ACE2 in the human male testes, which may suggest another route to COVID-19 infection. This may also explain the increased vulnerability of males to COVID-19 infection (Liu et al. 2020; Wang and Xu 2020).

Another study on patients who suffered from heart failure found that the plasma concentrations of ACE2 were higher in males than in females (Sama et al. 2020). One study regarding patients with diabetes, a common comorbidity of COVID-19 infection, found that serum ACE2 activity was nearly $30 \%$ higher in male patients than female patients (Soro-Paavonen et al. 2012; Garg et al. 2020). In patients with comorbidities associated with COVID-19 infection, male patients have a higher expression and activity of ACE2, which could explain increased COVID-19 severity and fatality.

Regulatory effects of estrogen on ACE2 may also explain the lower severity and fatality among female patients. When SARSCoV-2 binds to ACE2, the expression of ACE2 is downregulated, which exacerbates respiratory infection and severity (Hoffmann et al. 2020). Studies have shown that estrogen can upregulate the expression of ACE2, and one such study using atrial tissue from elderly males undergoing heart surgery found that the administration of estradiol to atrial tissue raised ACE2 expression (Bukowska et al. 2017; Gagliardi et al. 2020). This display of an up-regulatory mechanism may provide an explanation for better outcomes in females. This upregulation may be able to counteract the downregulation caused by viral entry of SARS-CoV-2, leading to better outcomes in female patients.

However, some argue that soluble plasma ACE2 levels do not provide an indication of COVID-19 risk. Instead, because SARS-CoV-2 binds to membrane ACE2, the level of membrane ACE2 gives a more relevant insight in this matter (Leow 2020). Nonetheless, more research needs to be done in this area. 


\section{Crosstalk Between Androgen and Transmembrane Protease} Serine 2 (TMPRSS2)

Another key feature in the entry of COVID-19 into the cell is the transmembrane protease serine 2 (TMPRSS2). TMPRSS2 is necessary for the priming of the viral $\mathrm{S}$ protein of COVID19 , and it essential for the spread of COVID-19 in the body (Hoffmann et al. 2020). Androgen receptors (ARs) play a key role in the transcription of TMPRSS2 (Fig. 1). This may explain the predominance of males to COVID-19 infection, fatality, and severity because males tend to have a higher expression and activation of ARs than females, which is due to the presence of dihydrotestosterone (DHT) (Fig. 1). Furthermore, SARS-CoV-2 has been shown to infect Type II pneumocytes in the lungs, and the presence of androgens and ARs in these cells is correlated with TMPRSS2 expression (Goren et al. 2020; Montopoli et al. 2020; Wambier et al. 2020). The positive effects of androgens on TMPPRSS2 expression may provide further explanation for increased likelihood of disparate outcomes of COVID-19 in male patients.

\section{Greater Immune Responses in Females Than Males}

Female COVID-19 patients may also experience lower severity and fatality rates than male patients due to their enhanced immune responses (Ruggieri et al. 2016). It is widely accepted that females have more vigorous cell-mediated and humoral immune responses (Fish 2008). Studies have shown that several immune cells - including macrophages, T cells, natural killer cells, and B cells - contain estrogen receptors, which shows that they can be regulated by estrogen (Klein et al. 2015). The enhanced features of the female immune response tend to decrease with age, further corroborating estrogen's positive effects on the immune system (Giefing-Kroll et al. 2015). Additionally, several studies have shown that estrogens promote antibody responses (Ruggieri et al. 2016). One study on birds found that, in response to an activation of the immune system, female birds displayed a higher antibody response. Furthermore, a study regarding the female rhesus macaque found that both antibody secreting-cells and antibody levels were highest before ovulation, illustrating the positive effects of female sex hormones on antibody levels (Klein and Flanagan 2016). Furthermore, studies have shown found that human females have an increased antibody response to vaccinations compared to males (Klein et al. 2015; Klein and Flanagan 2016). In fact, estrogen has been shown to promote Immunoglobin $\mathrm{G}$ (IgG) and Immunoglobin M (IgM), while testosterone inhibited this expression (Ruggieri et al. 2016). A recent study of COVID-19 patients has shown increased levels of IgG and IgM after COVID-19 infection, indicating that presence of these antibodies can influence the outcome of
Fig. 1 Regulation of COVID-19 severity and fatality by sex hormones. Females have aromatase, the enzyme that converts androgen substrates into estrogen. On the other hand, males have steroid $5 \alpha$ reductase, the enzyme that is responsible for the conversion of testosterone into dihydrotestosterone (DHT). In case of males, DHT activates androgen receptor (AR) that binds to the androgen response element (ARE) present in the promoter of TMPRSS2 gene, leading to its transcription. This ultimately results into enhanced processing of viral spike protein for greater entry and spread of SARS-CoV-2 into host cells. On the other hand, in females, estrogen activates estrogen receptor (ER), which binds to the estrogen response element (ERE) present in the promoter of eNOS gene to drive its transcription and catalyze the formation of nitric oxide (NO) from $\mathrm{L}$-arginine. This $\mathrm{NO}$ is involved in vasodilation as well as inhibition of viral replication

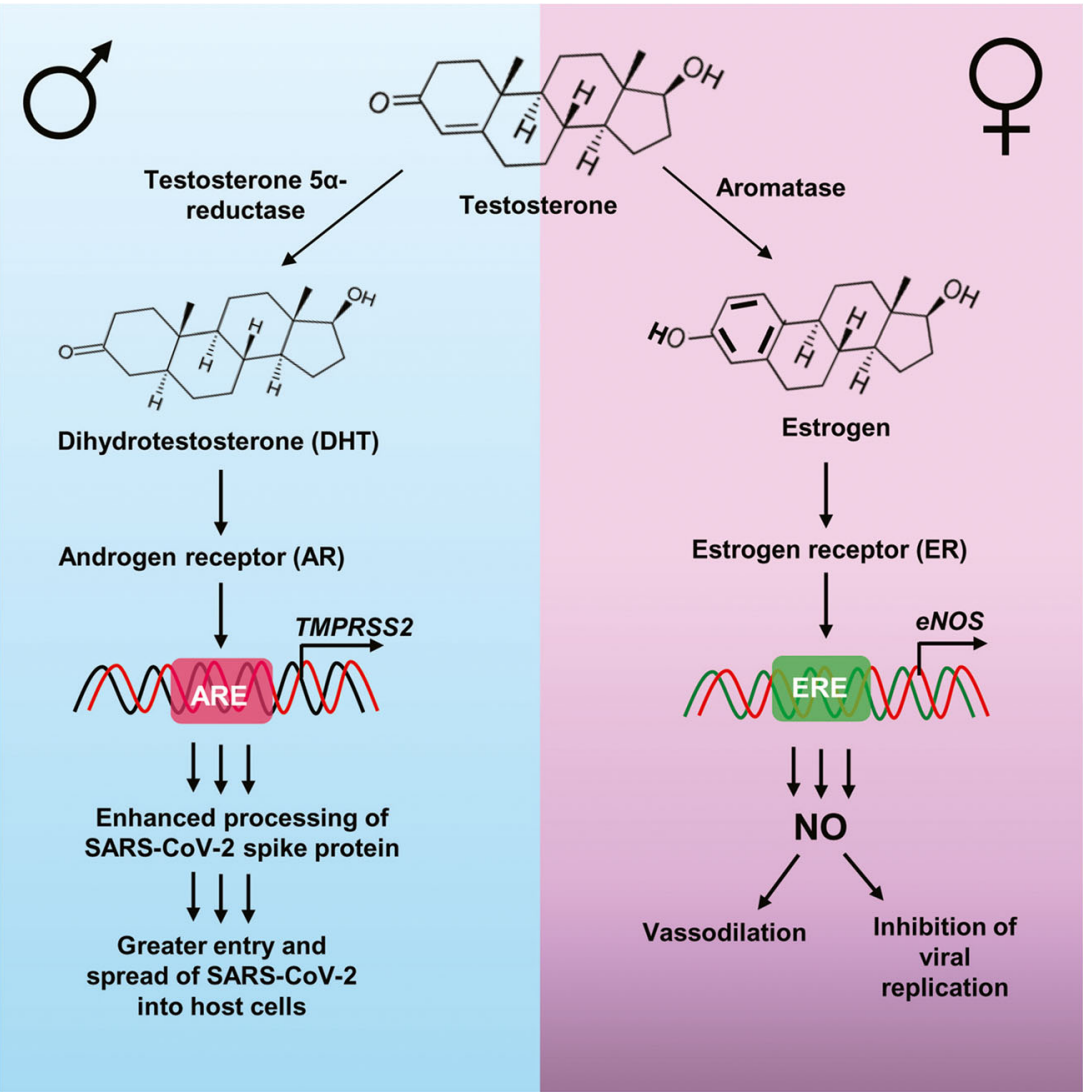


COVID-19 infection (Hou et al. 2020). In all, females see enhanced immune responses compared to males due to sex hormone influences, which explains the sex disparities in COVID-19 outcomes.

\section{Greater Levels of Nitric Oxide (NO) in Females Than Males: A Weapon in the Fight Against Viral Infections}

Nitric oxide (NO) is a gaseous component of the immune system that assists in the elimination of pathogens and foreign species from the body. More importantly, NO is capable of inhibiting the replication of viruses (Rimmelzwaan et al. 1999; Saura et al. 1999). Studies have shown that the production of NO is enhanced by estrogen via estrogen receptormediated transcriptional upregulation of endothelial nitric oxide synthase (eNOS) (MacRitchie et al. 1997) (Fig. 1). A study on bronchial epithelial cells in humans found that biologically relevant concentrations of estrogens significantly increased the expression of eNOS and the production of NO in these cells (Townsend et al. 2011; Wink et al. 2011). The impact of estrogen on NO may provide a further layer of protection against COVID-19, and the role of nitric oxide as virus replication inhibitor can explain why females tend to experience less severe outcomes of COVID-19 infection (Fig. 1).

Moreover, it has been found that NO is an important physiological vasodilator where it exerts vasodilation via activation of the guanylyl cyclase - cyclic GMP pathway (Archer et al. 1994). It has been found that COVID-19 infection usually becomes severe and deadly in persons with preexisting cardiovascular problems and hypertension (Cao et al. 2020; Pahan and Pahan 2020). Therefore, estrogen-dependent eNOS-NO-cGMP-vasodilation pathway could be a boon for female COVID-19 patients.

\section{Smoking, Prevalence of Comorbidities, and Decreased Physician Consultation Do Not Help Males in the Fight Against COVID-19}

Finally, gendered differences in behaviors may also provide an explanation for the gender disparity seen in COVID-19 outcomes. For example, studies have shown that smoking is associated with an increased risk for adverse outcomes of COVID-19. Research has shown that smoking increases the expression of the SARS-CoV-2 receptor, ACE2, in the lungs, which increases the possible sites of viral entry. Patterns from the United States, Italy, and China-the most affected nations - show that men have higher rates of smoking than women (Cai et al. 2020; Cai 2020; Walter and McGregor 2020). This trend is depicted globally, as well, which can provide additional rationale for the gendered differences in COVID-19 outcomes (Pampel 2006). Furthermore, there exist some social norms that discourage men from seeking treatment or physician consultation. As a result, men often delay seeking treatment, which can increase the probability of adverse outcomes after COVID-19 infection (Banks 2001; Gebhard et al. 2020). Finally, the presence of comorbidities increases the risk of adverse outcomes to COVID-19, and males are overrepresented compared to females in patients with the common comorbidities for COVID- 19 . Hypertension is often listed as the most common comorbidity in patients hospitalized with COVID-19, and a study has shown that males under the age of 65 have higher levels of hypertension than females (Everett and Zajacova 2015; Gebhard et al. 2020). Taken together, males are more susceptible to severity and fatality from COVID-19 than females probably due to the activation of the DHT-AR-TMPRSS2 pathway, lack of protection from female sex hormone estrogen, higher levels of ACE2 in different organs, greater incidence of smoking, lesser levels of $\mathrm{NO}$, and decreased immune response (Fig. 2).

\section{Possible Therapeutic Avenues for Controlling Gender- specific COVID-19 Cases}

Currently, research regarding possible therapeutic options for COVID-19 cases is focused on methods of modulating the expression of ACE2 and TMPRSS2 in the body, as these are the molecules associated with the entry of SARS-CoV-2 in the cell.

Upon binding to ACE2 to gain entry into the body, the SARS-CoV-2 virus subsequently downregulates ACE2 expression, exacerbating respiratory issues and negatively impacting organ function. Under non-pathological conditions, ACE2 is necessary for maintaining respiratory health. Thus, increasing ACE2 expression in the body after SARS-CoV-2 infection may help mitigate the symptoms of COVID-19. Some studies have found that treatment with recombinant human ACE2 helped to improve lung impairment after COVID19 infection (Gheblawi et al. 2020; Vaduganathan et al. 2020). Others have suggested that treatment of soluble ACE2 may create a biological decoy for SARS-CoV-2, leaving the membrane-bound ACE2 intact (Leow 2020; Lumbers et al. 2020). Additionally, as discussed earlier, estrogen can upregulate the expression of ACE2, thus creating a protective mechanism against some of the complications during COVID-19 infection (Bukowska et al. 2017). Therefore, estrogen treatment may be a potential avenue for COVID-19 in postmenopausal females. Furthermore, given that the positive effects of estradiol administration on ACE2 expression was observed in the atrial tissue of elderly males, estrogen treatment may even be a viable therapeutic option for older populations of male patients (Bukowska et al. 2017).

TMPRSS2 is affected by ARs; thus, modulating AR expression may present therapeutic options for COVID-19. Inhibition of ARs can be achieved through AR antagonists, inhibitors to androgen synthesis, and antigonadotropins 
Fig. 2 Schematic describing possible mechanisms by which SARS-CoV-2 infection leads to different outcome in males and females. Red for worsening and green for protective

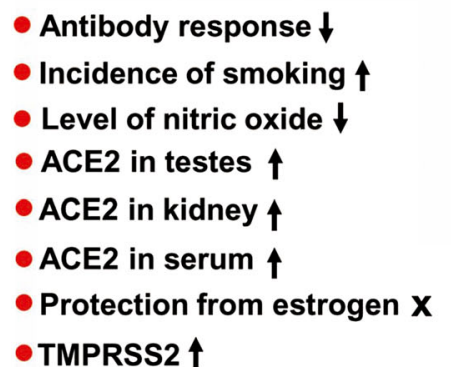

- Antibody response $\uparrow$ - Incidence of smoking $\downarrow$

- Level of nitric oxide $\uparrow$

- ACE2 in ovary $x$

- ACE2 in kidney $\downarrow$

- ACE2 in serum $\downarrow$

- Protection from estrogen $\uparrow$

- TMPRSS2 $\downarrow$

- TMPRSS2 $\uparrow$
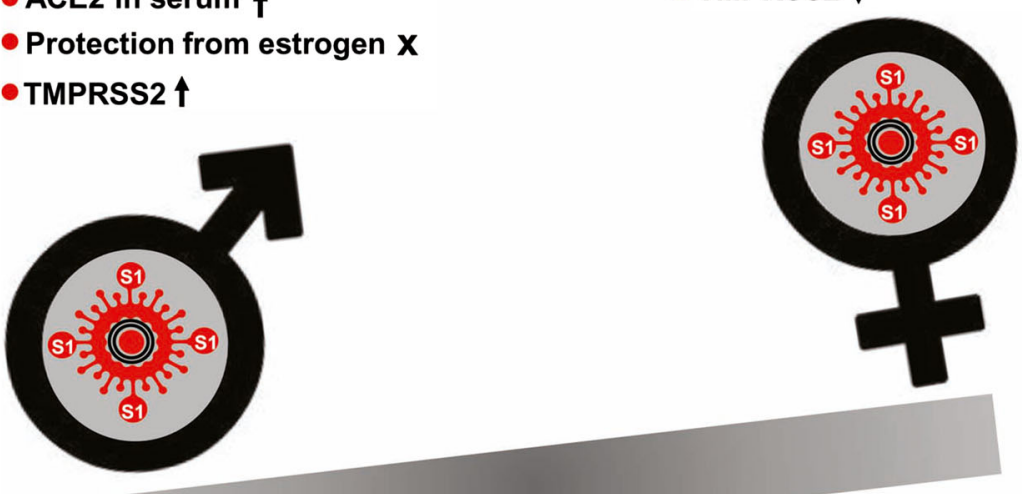

(Goren et al. 2020). However, due to the possible protective effects of estrogen, further research on the use of antigonadotropins is necessary. Therapies targeting ARs are especially important for prostate cancer patients, due to their high expression of TMPRSS2. A study of prostate cancer patients found that those who were receiving androgendeprivation therapies were less likely to develop COVID-19; and, there were no fatalities among the patients receiving androgen-deprivation therapies (Montopoli et al. 2020). These results provide preliminary evidence regarding the benefits of targeting the androgen receptor to mitigate COVID-19 risk. Inhibiting TMRSS2 directly is another option for COVID-19 therapies. Camostat mesylate has been widely studied as an inhibitor to TMPRSS2, and studies have shown that it can be effective in preventing infection by SARS-CoV2 (Montopoli et al. 2020; Vaduganathan et al. 2020). Another study showed that combining camostat mesylate with inhibitors of other proteases was successful in blocking SARSCoV-2 into the body (Gheblawi et al. 2020) (Tables 1 and 2).

\section{Conclusions}

In conclusion, several reports point to the sex and gender differences in COVID-19 outcomes. Though the current evidence does not suggest a sex or gender difference COVID-19
Table 1 Influence of Sex Hormones on ACE2 throughout the Body

\begin{tabular}{|c|c|c|c|}
\hline Organ & Sex Hormones & Effect on ACE2 & Impact on COVID-19 \\
\hline Lungs & $17 \beta$-estradiol & Lower levels of ACE2 mRNA & Protective effects against COVID-19 \\
\hline \multirow[t]{2}{*}{ Heart } & Estrogen & Inhibitory effect on ACE2 activity & Protective effects against COVID-19 \\
\hline & Testosterone & $\begin{array}{l}\text { Stimulatory effect on ACE2 } \\
\text { activity }\end{array}$ & $\begin{array}{l}\text { Increased vulnerability to adverse } \\
\text { outcomes of COVID-19 }\end{array}$ \\
\hline Kidney & Estrogen/Estradiol & $\begin{array}{l}\text { Inhibitory effect on ACE2 activity } \\
\text { and expression }\end{array}$ & Protective effects against COVID-19 \\
\hline
\end{tabular}

This table details the differential effects of male and female sex hormones on the activity and expression of ACE2 in the lungs, heart, and kidney. These organs are important targets for SARS-CoV-2, so elucidating the differential effects of sex hormones on ACE2 in these organs is a necessary step in developing effective therapeutics (Liu et al. 2010; Dalpiaz et al. 2015; Ruggieri et al. 2016) 
Table 2 How Sex Alters Expression of Binding Targets of SARS-CoV2

\begin{tabular}{|c|c|c|}
\hline & ACE2 & TMPRSS2 \\
\hline $\begin{array}{l}\text { Female Sex } \\
\quad \text { Hormon- } \\
\quad \text { es: } \\
\text { Estrogen } \\
\text { Estradiol }\end{array}$ & $\begin{array}{l}\text { Inhibitory effect on renal } \\
\text { ACE2 activity and } \\
\text { expression } \\
\text { Inhibitory effect on } \\
\text { cardiac ACE2 activity } \\
\text { Inhibitory effect on } \\
\text { bronchial ACE2 } \\
\text { mRNA } \\
\text { Therapeutic } \\
\text { administration of } \\
\text { estrogen may } \\
\text { upregulate ACE2 to } \\
\text { compensate for } \\
\text { downregulation by } \\
\text { SARS-CoV-2 }\end{array}$ & $\begin{array}{l}\text { Female sex hormones have } \\
\text { little effect on TMPRSS } 2 \\
\text { expression }\end{array}$ \\
\hline $\begin{array}{l}\text { Male Sex } \\
\text { Hormon- } \\
\text { es: } \\
\text { Testosterone } \\
\text { Androgens }\end{array}$ & $\begin{array}{l}\text { Overall ACE2 activity is } \\
\text { higher in males } \\
\text { Renal ACE2 activity and } \\
\text { expression is higher in } \\
\text { males } \\
\text { Stimulatory effect on } \\
\text { cardiac ACE2 activity } \\
\text { ACE2 is found in testes } \\
\text { Plasma concentrations of } \\
\text { ACE2 are higher in } \\
\text { males }\end{array}$ & $\begin{array}{l}\text { Males have higher expression } \\
\text { of androgen receptors, } \\
\text { which play a role in } \\
\text { transcription of TMPRSS2 }\end{array}$ \\
\hline
\end{tabular}

This table provides a summary regarding how biological sex influences the expression and activity of ACE2 and TMPRSS2, the mediators of entry of SARS-CoV-2 into the body (Liu et al. 2010; Soro-Paavonen et al. 2012; Dalpiaz et al. 2015; Garg et al. 2020; Goren et al. 2020; Montopoli et al. 2020; Sama et al. 2020; Stelzig et al. 2020; Wambier et al. 2020; Wang and Xu 2020)

infection, male patients tend to have both higher severity and fatality rates. These disparities may be due to higher levels of ACE2 and TMPRSS2 in males, as well as hormonal influences on the immune response. Gender differences in behavior can also contribute to the greater severity and fatality in COVID-19 observed among men. Men tend to make up a greater proportion of smokers and patients with COVID-19associated comorbidities, while also being less likely to seek out medical health for illness. The combination of these factors could lead to poorer COVID-19 outcomes. SARS-CoV-2 relies on ACE2 and TMPRSS2 to enter the body; thus, treatment targeting the levels of these proteins could be possible therapies for COVID-19 infection. Supplementing ACE2 levels in the body through treatment with soluble ACE2 may be able to mitigate severe symptoms, while TMPRSS2 inhibitors can prevent SARS-CoV-2 entry altogether. Treatment with estrogen has been shown to increase ACE2 levels, but further research needs to be done regarding its effectiveness in COVID-19 cases. Understanding of these sex and gender differences is necessary, as it can help identify vulnerable populations and develop specific and effective therapeutic strategies.

Acknowledgements This study was supported by grants from NIH (AG050431, AG069229, NS108025, and AT010980), the Zenith Fellows Award (ZEN-17-438829) from Alzheimer's Association and merit awards (1I01BX003033 and 1I01BX005002) from US Department of Veterans Affairs to KP. Moreover, KP is the recipient of a Research Career Scientist Award (1IK6 BX004982) from the Department of Veterans Affairs.

\section{Compliance with Ethical Standards}

Conflict of Interest None.

\section{References}

Ambrosino I, Barbagelata E, Ortona E, Ruggieri A, Massiah G, Giannico OV, Politi C, Moretti AM (2020) Gender differences in patients with COVID-19: a narrative review. Monaldi Arch Chest Dis 90(2). https://doi.org/10.4081/monaldi.2020.1389

Archer SL, Huang JM, Hampl V, Nelson DP, Shultz PJ, Weir EK (1994) Nitric oxide and cGMP cause vasorelaxation by activation of a charybdotoxin-sensitive $\mathrm{K}$ channel by cGMP-dependent protein kinase. Proc Natl Acad Sci U S A 91:7583-7587

Banks I (2001) No man's land: men, illness, and the NHS. BMJ 323: $1058-1060$

Bukowska A, Spiller L, Wolke C, Lendeckel U, Weinert S, Hoffmann J, Bornfleth P, Kutschka I, Gardemann A, Isermann B, Goette A (2017) Protective regulation of the ACE2/ACE gene expression by estrogen in human atrial tissue from elderly men. Exp Biol Med (Maywood) 242:1412-1423

Cai H (2020) Sex difference and smoking predisposition in patients with COVID-19. Lancet Respir Med 8:e20

Cai G, Bosse Y, Xiao F, Kheradmand F, Amos CI (2020) Tobacco smoking increases the lung gene expression of ACE2, the receptor of SARS-CoV-2. Am J Respir Crit Care Med 201:1557-1559

Cao Y, Zhang M, Guo Y, Zhang Y (2020) The overlooked chamber in coronavirus disease 2019. ESC Heart Fail. https://doi.org/10.1002/ ehf2.12976

Chappell MC, Marshall AC, Alzayadneh EM, Shaltout HA, Diz DI (2014) Update on the Angiotensin converting enzyme 2Angiotensin (1-7)-MAS receptor axis: fetal programing, sex differences, and intracellular pathways. Front Endocrinol (Lausanne) 4: 201

Dalpiaz PL, Lamas AZ, Caliman IF, Ribeiro RF Jr, Abreu GR, Moyses MR, Andrade TU, Gouvea SA, Alves MF, Carmona AK, Bissoli NS (2015) Sex hormones promote opposite effects on ACE and ACE2 activity, hypertrophy and cardiac contractility in spontaneously hypertensive rats. PLoS One 10:e0127515

Everett B, Zajacova A (2015) Gender differences in hypertension and hypertension awareness among young adults. Biodemography Soc Biol 61:1-17

Fish EN (2008) The X-files in immunity: sex-based differences predispose immune responses. Nat Rev Immunol 8:737-744

Gagliardi MC, Tieri P, Ortona E, Ruggieri A (2020) ACE2 expression and sex disparity in COVID-19. Cell Death Discov 6:37

Garg S et al (2020) Hospitalization rates and characteristics of patients hospitalized with laboratory-confirmed coronavirus disease 2019 COVID-NET, 14 States, March 1-30, 2020. MMWR Morb Mortal Wkly Rep 69:458-464 
Gargaglioni LH, Marques DA (2020) DA (2020) Let's talk about sex in the context of COVID-19. J Appl Physiol (1985) 128:1533-1538

Gebhard C, Regitz-Zagrosek V, Neuhauser HK, Morgan R, Klein SL (2020) Impact of sex and gender on COVID-19 outcomes in Europe. Biol Sex Differ 11:29

Gheblawi M, Wang K, Viveiros A, Nguyen Q, Zhong JC, Turner AJ, Raizada MK, Grant MB, Oudit GY (2020) Angiotensin-Converting Enzyme 2: SARS-CoV-2 Receptor and Regulator of the ReninAngiotensin System: Celebrating the 20th Anniversary of the Discovery of ACE2. Circ Res 126:1456-1474

Giefing-Kroll C, Berger P, Lepperdinger G, Grubeck-Loebenstein B (2015) How sex and age affect immune responses, susceptibility to infections, and response to vaccination. Aging Cell 14:309-321

Goren A, McCoy J, Wambier CG, Vano-Galvan S, Shapiro J, Dhurat R, Washenik K, Lotti T (2020) What does androgenetic alopecia have to do with COVID-19? An insight into a potential new therapy. Dermatol Ther 33(4):e13365

Grasselli G et al (2020) Baseline characteristics and outcomes of 1591 patients infected with SARS-CoV-2 admitted to ICUs of the Lombardy Region, Italy. JAMA 323:1574-1581

Guan WJ et al (2020) Clinical characteristics of coronavirus disease 2019 in China. N Engl J Med 382:1708-1720

Hoffmann M, Kleine-Weber H, Schroeder S, Kruger N, Herrler T, Erichsen S, Schiergens TS, Herrler G, Wu NH, Nitsche A, Muller MA, Drosten C, Pohlmann S (2020) SARS-CoV-2 cell entry depends on ACE2 and TMPRSS2 and Is blocked by a clinically proven protease inhibitor. Cell 181:271-280 e278

Hou H, Wang T, Zhang B, Luo Y, Mao L, Wang F, Wu S, Sun Z (2020) Detection of $\operatorname{IgM}$ and $\operatorname{IgG}$ antibodies in patients with coronavirus disease 2019. Clin Transl Immunol 9:e01136

Huang C et al (2020) Clinical features of patients infected with 2019 novel coronavirus in Wuhan, China. Lancet 395:497-506

Jain U (2020) Effect of COVID-19 on the organs. Cureus 12:e9540

Jin JM, Bai P, He W, Wu F, Liu XF, Han DM, Liu S, Yang JK (2020) Gender differences in patients with COVID-19: focus on severity and mortality. Front Public Health 8:152

Klein SL, Flanagan KL (2016) Sex differences in immune responses. Nat Rev Immunol 16:626-638

Klein SL, Marriott I, Fish EN (2015) Sex-based differences in immune function and responses to vaccination. Trans R Soc Trop Med Hyg 109:9-15

Krueger A, Gunn JKL, Watson J, Smith AE, Lincoln R, Huston SL, Dirlikov E, Robinson S (2020) Characteristics and outcomes of contacts of COVID-19 patients monitored using an automated symptom monitoring tool - maine, May-June 2020. MMWR Morb Mortal Wkly Rep 69:1026-1030

Leow MKS (2020) Clarifying the controversial risk-benefit profile of soluble ACE2 in COVID-19. Crit Care 24:396

Liu J, Ji H, Zheng W, Wu X, Zhu JJ, Arnold AP, Sandberg K (2010) Sex differences in renal angiotensin converting enzyme 2 (ACE2) activity are 17beta-oestradiol-dependent and sex chromosome-independent. Biol Sex Differ 1:6

Liu X, Chen Y, Tang W, Zhang L, Chen W, Yan Z, Yuan P, Yang M, Kong S, Yan L, Qiao J (2020) Single-cell transcriptome analysis of the novel coronavirus (SARS-CoV-2) associated gene ACE2 expression in normal and non-obstructive azoospermia (NOA) human male testes. Sci China Life Sci 63:1006-1015

Lumbers ER, Delforce SJ, Pringle KG, Smith GR (2020) The lung, the heart, the novel coronavirus, and the renin-angiotensin system; The need for clinical trials. Front Med (Lausanne) 7:248

Machhi J, Herskovitz J, Senan AM, Dutta D, Nath B, Oleynikov MD, Blomberg WR, Meigs DD, Hasan M, Patel M, Kline P, Chang RC, Chang L, Gendelman HE, Kevadiya BD (2020) The Natural history, pathobiology, and clinical manifestations of SARS-CoV-2 infections. J Neuroimmune Pharmacol 15:359-386
MacRitchie AN, Jun SS, Chen Z, German Z, Yuhanna IS, Sherman TS, Shaul PW (1997) Estrogen upregulates endothelial nitric oxide synthase gene expression in fetal pulmonary artery endothelium. Circ Res 81:355-362

Martinez-Rojas MA, Vega-Vega O, Bobadilla NA (2020) Is the kidney a target of SARS-CoV-2? Am J Physiol Renal Physiol 318:F1454 F1462

Montopoli M, Zumerle S, Vettor R, Rugge M, Zorzi M, Catapano CV, Carbone GM, Cavalli A, Pagano F, Ragazzi E, Prayer-Galetti T, Alimonti A (2020) Androgen-deprivation therapies for prostate cancer and risk of infection by SARS-CoV-2: a population-based study $(\mathrm{N}=4532)$. Ann Oncol 31:1040-1045

Pahan P, Pahan K (2020) Smooth or risky revisit of an old malaria drug for COVID-19? J Neuroimmune Pharmacol 15:174-180

Pampel FC (2006) Global patterns and determinants of sex differences in smoking. Int J Comp Sociol 47:466-487

Pinto BGG, Oliveira AER, Singh Y, Jimenez L, Goncalves ANA, Ogava RLT, Creighton R, Schatzmann Peron JP, Nakaya HI (2020) ACE2 expression is increased in the lungs of patients with comorbidities associated with severe COVID-19. J Infect Dis 222:556-563

Rimmelzwaan GF, Baars MM, de Lijster P, Fouchier RA, Osterhaus AD (1999) Inhibition of influenza virus replication by nitric oxide. J Virol 73:8880-8883

Ruggieri A, Anticoli S, D'Ambrosio A, Giordani L, Viora M (2016) The influence of sex and gender on immunity, infection and vaccination. Ann Ist Super Sanita 52:198-204

Sama IE, Ravera A, Santema BT, van Goor H, Ter Maaten JM, Cleland JGF, Rienstra M, Friedrich AW, Samani NJ, Ng LL, Dickstein K, Lang CC, Filippatos G, Anker SD, Ponikowski P, Metra M, van Veldhuisen DJ, Voors AA (2020) Circulating plasma concentrations of angiotensin-converting enzyme 2 in men and women with heart failure and effects of renin-angiotensin-aldosterone inhibitors. Eur Heart J 41:1810-1817

Saura M, Zaragoza C, McMillan A, Quick RA, Hohenadl C, Lowenstein JM, Lowenstein CJ (1999) An antiviral mechanism of nitric oxide: inhibition of a viral protease. Immunity 10:21-28

Sharma A, Garcia G Jr, Wang Y, Plummer JT, Morizono K, Arumugaswami V, Svendsen CN (2020) Human iPSC-derived cardiomyocytes are susceptible to SARS-CoV-2 infection. Cell Rep Med 1:100052

Soro-Paavonen A, Gordin D, Forsblom C, Rosengard-Barlund M, Waden J, Thorn L, Sandholm N, Thomas MC, Groop PH, FinnDiane Study G (2012) Circulating ACE2 activity is increased in patients with type 1 diabetes and vascular complications. J Hypertens 30:375-383

Stelzig KE, Canepa-Escaro F, Schiliro M, Berdnikovs S, Prakash YS, Chiarella SE (2020) Estrogen regulates the expression of SARSCoV-2 receptor ACE2 in differentiated airway epithelial cells. Am J Physiol Lung Cell Mol Physiol 318:L1280-L1281

Stokes EK, Zambrano LD, Anderson KN, Marder EP, Raz KM, El Burai Felix S, Tie Y, Fullerton KE (2020) Coronavirus disease 2019 case surveillance - United States, January 22-May 30, 2020. MMWR Morb Mortal Wkly Rep 69:759-765

Team TNCPERE (2020) The epidemiological characteristics of an outbreak of 2019 novel coronavirus disease (COVID-19). China CDC Weekly 2:113-122

Tian S, Hu N, Lou J, Chen K, Kang X, Xiang Z, Chen H, Wang D, Liu N, Liu D, Chen G, Zhang Y, Li D, Li J, Lian H, Niu S, Zhang L, Zhang J (2020) Characteristics of COVID-19 infection in Beijing. J Infect 80:401-406

Townsend EA, Meuchel LW, Thompson MA, Pabelick CM, Prakash YS (2011) Estrogen increases nitric-oxide production in human bronchial epithelium. J Pharmacol Exp Ther 339:815-824

Vaduganathan M, Vardeny O, Michel T, McMurray JJV, Pfeffer MA, Solomon SD (2020) Renin-angiotensin-aldosterone system inhibitors in patients with Covid-19. N Engl J Med 382:1653-1659 
Vickers C, Hales P, Kaushik V, Dick L, Gavin J, Tang J, Godbout K, Parsons T, Baronas E, Hsieh F, Acton S, Patane M, Nichols A, Tummino P (2002) Hydrolysis of biological peptides by human angiotensin-converting enzyme-related carboxypeptidase. J Biol Chem 277:14838-14843

Walter LA, McGregor AJ (2020) Sex- and gender-specific observations and implications for COVID-19. West J Emerg Med 21:507-509

Wambier CG, Goren A, Vano-Galvan S, Ramos PM, Ossimetha A, Nau G, Herrera S, McCoy J (2020) Androgen sensitivity gateway to COVID-19 disease severity. Drug Dev Res 81:771-776

Wang Z, Xu X (2020) scRNA-seq profiling of human testes reveals the presence of the ACE2 receptor, a target for SARS-CoV-2 Infection in spermatogonia\&nbsp;leydig and sertoli cells. Cells 9(4):920

Wink DA, Hines HB, Cheng RY, Switzer CH, Flores-Santana W, Vitek MP, Ridnour LA, Colton CA (2011) Nitric oxide and redox mechanisms in the immune response. J Leukoc Biol 89:873-891

Wortham JM et al (2020) Characteristics of persons who died with COVID-19 - United States, February 12-May 18, 2020. MMWR Morb Mortal Wkly Rep 69:923-929
Yanez ND, Weiss NS, Romand JA, Treggiari MM (2020) COVID-19 mortality risk for older men and women. BMC Public Health 20: 1742

Yuen KS, Ye ZW, Fung SY, Chan CP, Jin DY (2020) SARS-CoV-2 and COVID-19: The most important research questions. Cell Biosci 10: 40

Zaman MA, Oparil S, Calhoun DA (2002) Drugs targeting the reninangiotensin-aldosterone system. Nat Rev Drug Discov 1:621-636

Zhou F, Yu T, Du R, Fan G, Liu Y, Liu Z, Xiang J, Wang Y, Song B, Gu X, Guan L, Wei Y, Li H, Wu X, Xu J, Tu S, Zhang Y, Chen H, Cao B (2020) Clinical course and risk factors for mortality of adult inpatients with COVID-19 in Wuhan, China: a retrospective cohort study. Lancet 395:1054-1062

Publisher's Note Springer Nature remains neutral with regard to jurisdictional claims in published maps and institutional affiliations. 